\title{
Growing Pains, Evolution and Progress
}

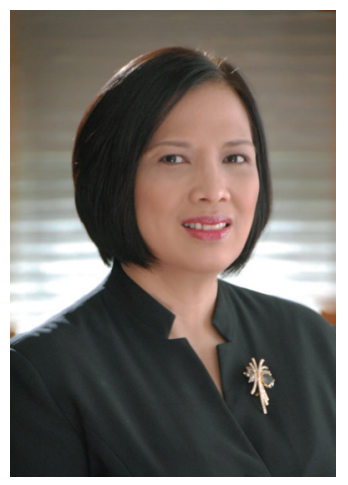

Six issues over the last three years saw JAFES undergo a remarkable transformation - from a journal with humble operations in the heart of Manila-to a publication that dares to be noticeable by the world.

Since 2013, we have shifted to Open Access and made all articles published from 2011 to the present available online for download in portable document formats, without charging any manuscript processing fees to authors. This year, through the Open Journal Systems of the US Public Knowledge Project, we shall be launching the new JAFES website platform with electronic journal management. This time, all articles, while remaining free to download, shall likewise be viewable in HTML; moreover, all transactions, from editorial board deliberation to peer review, from submission to publication, shall be electronic, in keeping with the digital age. Compared to previous years, in which our issues are released regularly each May and November, now, articles will become available online as soon as they are completely processed; and an issue shall comprise a collation of articles from the preceding six months. In addition, changes in editorial policies, ethical considerations, copyright, authorship, and author instructions-which are stated in the journal's end pages-are products of enhanced awareness following our participation in journal association conferences.

We are doing all of these, not only to further enhance our capacity to process manuscript submissions into high quality publications, but to also ensure that these articles are available to all: on time, online. Indeed, we live by our ideals of "promoting the exchange of knowledge, encouraging research initiatives, facilitating collaborative research, and publishing key findings in a timely and focused manner for endocrine patients and professionals in the ASEAN region."

Evolution did have its share of growing pains. While at one point, the team hoped that the work will become easier over time, there remains challenges yet to be hurdled. Indexing in the major services, such as PubMed, Scopus, and even ISI, may be delayed for the moment, but it is not impossible: it shall be achievable in time. Sustainability is another major concern. The continued support from the societies that make up the AFES, in terms of manuscript submissions, peer reviewer referrals, editorial participation, and finances, is absolutely necessary for the journal to keep going. Reviewer/editor fatigue, external pressures, health concerns, and staff turn-over, are constant reminders of our mortality; yet the mission continues.

We would like to think that JAFES is an embodiment of the growing cooperation among Southeast Asian country endocrinology societies. It is a collective effort to make Southeast Asian data on endocrinology accessible and obtainable, not only to our region, but to all. It is evolving with the times, adapting to situations, and continually improving: a work in progress, in the truest sense.

We cannot reach this point and even think about the future without thinking of the end-all and be-all of this noble venture: the author, the reader, and the knowledge that connects one to the other, as it benefits patients in general. We dedicate this issue to you.

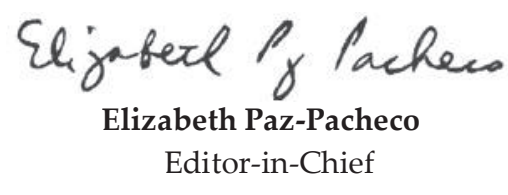

